\title{
Review of Mark Dsouza's Rationale-Based Defences in Criminal Law
}

Zachary Hoskins, University of Nottingham

ABSTRACT: Mark Dsouza's new book, Rationale-Based Defences in Criminal Law, aims to shed new light on the question of how to conceptualize justifications and excuses as defenses against criminal liability this debate. His offers an alternative to the common account on which justifications negate the wrongness of acts whereas excuses negate only the actor's blameworthiness but not the act's wrongness. Instead, Dsouza contends that the justification-excuse distinction is entirely a matter of the quality of the defendant's reasoning. His account of justifications is generally compelling, although his accounts of excuses and of the moral norms underlying the criminal law are less persuasive. Overall, however, Dsouza successfully establishes his quality-of-reasoning view as a viable competitor theory of justifications and excuses.

The question of how to conceptualize justifications and excuses as defenses against criminal liability is a topic that, despite extensive philosophical attention, continues to be among the most contentious issues in normative criminal law theory. Mark Dsouza's new book, Rationale-Based Defences in Criminal Law, aims to shed new light on this debate. This is an impressive piece of work: it is carefully reasoned, responsive to existing debates in criminal law theory, and always mindful of the practical implications of the theoretical claims it defends.

Dsouza's central target is what he calls the "wrongness hypothesis," a prominent view on which the key distinction between justifications and excuses is that 
justifications negate the wrongness of an offense, whereas excuses negate the agent's blameworthiness for the offense but not the wrongness of the offense itself. As the Model Penal Code puts it, “To say that someone's conduct is 'justified' ordinarily connotes that the conduct is thought to be right, or at least not undesirable," whereas “to say that someone's conduct is 'excused' ordinarily connotes that the conduct is thought to be undesirable but that for some reason the actor is not to be blamed for it."1

Contrary to the wrongness hypothesis, Dsouza contends that we should distinguish the justification of acts from the justification of actors, and that we should acknowledge that actors may be justified, and thus blameless, in committing acts that are themselves wrong. If so, then the distinction between justifications and excuses cannot be that excuses negate a person's blameworthiness even though the act itself was wrong (after all, justifications may function the same way). Thus, we need a different way of distinguishing justifications from excuses.

On Dsouza's alternative account, the distinction is entirely a matter of the quality of the defendant's reasoning. On his view, the criminal law is grounded on a system of underlying moral norms — what he calls a "conduct rule system." Importantly, this system of moral norms "operates independently of the doctrinal law designed by different jurisdictions to capture its content" (p. 14). This opens the possibility that a person may violate a criminal law butfor reasons that accord with the underlying system of moral norms. Such a person would be justified in her behavior. For example, someone who shoots and kills a person because she believes the person is threatening her life could be justified insofar as her reasons conform to underlying moral norms allowing for acts of self-defense.

\footnotetext{
1 Model Penal Code Commentaries Article 3, introduction, at 3.
} 
In other cases, however, a person's reasons for violating a law may not accord with these underlying norms, but she may still be excused if her reasons comport with society's normative expectations (which are not exhausted by the moral norms underlying the criminal law). Dsouza writes, "if society would normatively expect one of its members to respond to a situation in the same manner as the defendant did, then it would be hypocritical for it to use its criminal law to single out the defendant as being especially deserving of blame" (p. 177). In other words, whereas the question of justification is whether a defendant's reasons comport with the moral norms underlying the criminal law, the question of excuse is whether society has standing to condemn the defendant's reasoning, or whether instead this condemnation would be hypocritical.

His account is most clearly distinguished from theories based on the wrongness hypothesis in cases where either a person commits acts that he sincerely believes to be permissible but that are in fact wrongful, or a person commits acts that, unbeknownst to him, are not wrongful. As an example of the first type, Dsouza discusses the ca se of a police officer who shoots and kills an unarmed victim based on a genuine, albeit mistaken, belief that the person was armed and posed a danger to his own life (p. 98). In such a case, he contends that the officer is not merely excused (as the wrong ness hypothesis would imply) but actually justified, insofar as the officer, based on his sincere but mistaken assessment of the situation, acted for reasons that comport with the moral norms underlying the criminal law: in this case, the right to act in selfdefense.

As an example of the second type, Dsouza discusses the case of $R v$. Dadson, ${ }^{2}$ in which a constable shot and injured a thief trying to escape with wood from a copse (p. 96). The thief had two previous misdemeanor convictions for the same offense, and this

\footnotetext{
${ }^{2}$ R. v. Dadson (1850) 4 Cox CC 358.
} 
third offense constituted a felony under English law. The law permitted a constable to shoot to prevent the commission of a felony, but not to prevent the commission of a misdemeanor. The constable had not known, when he shot the thief, that this was the third offense and thus a felony. Therefore, although he had in fact acted permissibly, he had not known at the time about the facts that made his act permissible. The wrongness hypothesis implies that the constable was justified, in that his conduct was not itself wrongful. The court ruled, however, that the constable was not entitled to a justification defense. Dsouza agrees with the court's ruling and contends that his quality-ofreasoning view can explain why the court's decision was appropriate. He writes:

The mere circumstance of fortuitously having acted so as to find oneself in compliance with a justificatory conduct norm ... should not entitle the agent to a justificatory defence. Instead, in order to be entitled to a justificatory defence, the agent should have been motivated by a permissive conduct norm drawn from the system of norms underlying the criminal law. (p. 96)

Central to Dsouza's account, as these examples illustrate, is his view that a person can do the wrong thing but for the right reasons, or vice versa, and that whether she is justified is a matter of the rightness of her reasons, not the rightness of her actions. There is much to be said in favor of this sort of view, and indeed, Dsouza acknowledges that others have rejected the wrongness hypothesis on similar grounds. ${ }^{3}$ In what follows, however, I focus on two distinctive aspects of Dsouza's book, and raise concerns relating to each.

First, the book is ambitious in that it attempts to articulate and defend an account of the system of moral norms underlying the criminal law. This account is not strictly speaking necessary to Dsouza's central thesis. That is, his claim that a person is justified in her conduct if her reasoning comports with the system of

\footnotetext{
3 See, notably, Marcia Baron, “Justifications and Excuses," Ohio State Journal of Criminal Law 2 (2005): $387-406$.
} 
moral norms underlying the criminal law could be true even if he is wrong about the content or derivation of these underlying norms. Nevertheless, Dsouza offers an extended discussion of these norms, in part because he wants to show that his account of justifications generates intuitively plausible results in particular cases, and to do this he must flesh out the norms with which justified reasoning accords.

At the heart of Dsouza's account of the moral norms underlying the criminal law are what he calls "constituent rights." These are rights that correspond to constituent features of typical human beings. (He supplements this with an account of "posited rights," though I won't have space to discuss these here.) In particular, he follows Hobbes in citing self-preservation as a constituently human behavior and follows Hegel in citing as constituently human the recognition of other human beings as more than mere instruments to be used for our purposes (pp.50-53). Dsouza contends that these constituent features are not susceptible to moral praise or blame (any more than having opposable thumbs is susceptible to moral assessment). These features do ground certain constituent rights, however, such as the right to life and the right not to be used as a mere means. Helping to protect these constituent rights is a central function of the criminal law. In some instances, however, a person may violate a criminal law but for reasons that comport with these constituent rights. Consider the example mentioned above, in which a police officer, under the mistaken belief that an unarmed person is in fact armed and threatening him, is driven by a desire for self-preservation to kill the person. Dsouza regards such cases as paradigmatic instances of justification.

The strategy of drawing on constituent features of human beings to ground a system of underlying moral norms thus does a lot of work in Dsouza's account. I am skeptical about this line of argument, however, for a few reasons. First, he equivocates 
about the nature of these constituent human elements that are not susceptible to moral praise or blame: are they capacities or behaviors? In elaborating the view, he writes by analogy that it makes no sense to ask whether it is moral for us "to have opposable thumbs, or to be capable of walking on two feet, or to be able to choose our willed actions" (p. 51). This suggests that constituently human capacities are not susceptible to moral assessment. Then he writes, however, that it similarly "makes no sense to ask whether it is moral for a human to have behaved in a manner that was constituently human, even when doing so harms others" (ibid.). This suggests that it is not merely capacities but behaviors that can be immune to moral evaluation. His discussion in what follows indicates that he is more interested in constituently human behaviors than capacities. If this is correct, then his appeal to opposable thumbs, the capacity to walk on two feet, or the capacity to choose willed actions as illustrations is misleading. For although merely having opposable thumbs, being a biped, or being capable of rational choice falls outside the scope of moral evaluation, behaviors that issue from these features - using our thumbs to pull the trigger on a gun, stepping on an injured person in our path, or exercising our capacity for choice in various heinous ways - certainly are susceptible to moral evaluation.

Suppose, though, that having opposable thumbs and being bipeds are just illchosen analogies, and that Dsouza is centrally interested in constituently human behaviors. We must then ask what behaviors count as constituently human. My second reason for skepticism about this line of argument is that he devotes surprisingly little space to fleshing out these constituent behaviors. It's true, as Dsouza points out, that providing a full account of all such behaviors would be too big a project to tackle in this book. But his discussion is essentially limited to the two behaviors noted above: selfpreservation and recognition of others' humanity. What about other, less palatable 
behaviors, such as weak-willed, greedy, envious, or selfish behaviors? Are these not constituent behaviors of human beings? If not, why not? They are certainly widely manifested by human beings. Arguably selfishness is at least as prevalent in human beings as the recognition of others as not merely instrumental. We might understand the constituent behaviors as those that are distinctively human, but then selfpreservation behavior would be ruled out, as nonhuman animals exhibit survival instincts.

Dsouza makes clear that he does not take the constituent human behaviors he discusses to constitute an exhaustive list, so perhaps weak-willed, greedy, and other such behaviors would also be included on a comprehensive list. But if so, it follows on his account that such behaviors are logically prior to any system of moral norms, and thus (like self-preservation) are not subject to the blame conveyed by criminal sanctions. This is presumably a result he would find unacceptable.

Dsouza does tell us that constituently human behaviors may conflict, so that a given action may manifest one constituent behavior (say, self-preservation) and contradict another (say, recognition of others as not merely instrumental). He contends that, in such cases, these actions become susceptible to moral assessment. Perhaps, then, he could admit that greedy or selfish behaviors are constituently human, but then insist that actions issuing from these behaviors typically contradict other constitue ntly human behaviors. In such cases, actions emerging from greedy or selfish behaviors would be susceptible to moral evaluation. But if this is his view, he must make clear why an act that manifests a conflict between constituent human behaviors - neither of which is itself susceptible to moral assessment - is thus susceptible to such assessment. Why not say instead that, when behaviors are not morally assessable, conflicts issuing from these behaviors are similarly not morally assessable? 
Suppose we accept, however, that when actions manifest one constituent behavior but contradict another, the actions are themselves susceptible to moral assessment. So, in the example Dsouza discusses, actions motivated by self-preservation are not subject to moral evaluation unless they fail to recognize the humanity of others and treat them merely as tools. Notice, though (and this is my third reason for skepticism about his line of argument), that determining whether an action fails to respect others' humanity itself involves moral assessment. Thus, it is not quite true, as Dsouza claims, that actions issuing from constituent human behaviors are not susceptible to moral assessment unless they contradict other constituent human behaviors. Rather, all actions are susceptible to moral assessment to determine whether they conflict with other constituent behaviors.

Ultimately, I am not persuaded that Dsouza provides an intuitively appealing basis for deriving constituent rights. As I said, though, his central claim about justifications - namely, that one is justified in acting when one's reasons comport with the system of moral norms underlying the criminal justice system - does not depend on the particular derivation of these norms that he endorses. In my view, his rationalebased account of justifications and his rejection of the wrongness hypothesis are persuasive in their own right, regardless of my reservations about his derivation of the underlying norms.

The second distinctive aspect of Dsouza's account that I want to discuss is his analysis of excuses. As we have seen, a person is justified, on Dsouza's account, when her reasons for acting accord with the system of moral norms underlying the criminal law. She is excused when, although her reasons do not comport with these underlying norms, it would be hypocritical for society to blame her, because she has done what society would normatively expect of any of its members in the given circumstances. I 
think the gist of this account of excuses is plausible, but I do not think hypocrisy is the most useful way to characterize what is wrong with failing to excuse in such circumstances. Hypocrisy suggests that A holds B to a standard, or blames B for failing to meet a standard, that A himself fails to meet. For a society's failure to excuse a person's conduct to constitute hypocrisy, then, it must be the case that society holds the person to a standard to which it does not hold its members generally.

Now consider the commonly cited excuse of duress. We tend to think that committing crimes when under threat from another person is at least sometimes less blameworthy (or even blameless) insofar as it would be expecting too much of the agent to resist the threat. But notice that, although blaming in such cases may be unreasonable, it need not be hypocritical. If society consistently blames people who commit crimes under duress, then it is not holding some to a standard to which it does not hold others. The appropriate criticism of such a practice would be, instead, that society's treatment of its members reflects that its expectations are consistently too high.

Despite my reservations about Dsouza's derivation of the constituent rights underlying the criminal law, or his casting of excuses in terms of avoiding hypocrisy, I believe that his central line of argument - that the distinction between justifications and excuses hinges on the quality of the defendant's reasoning - is persuasive. Although others have endorsed a similar basis for the distinction, and thus have similarly rejected the wrongness hypothesis, Dsouza's extended defense of this view presents an important contribution to the ongoing debate on this thorny issue.

Earlier, I wrote that the book is ambitious in attempting to lay out the system of moral norms underlying the criminal law. It is in another respect modest. Dsouza acknowledges that he does not take himself to be providing a decisive line of argument 
for his view, or against the wrongness hypothesis, which he describes as "eminently plausible" (p. xvii). Indeed, he concludes, "I doubt that it is possible to provide any such proof. However, I hope that it does supply strong reasons to believe that the quality of reasoning-based model described here is a very good description of how the criminal law should be, because it is plausible, well founded and gives rise to desirable outcomes" (p. 179). In my view, Dsouza largely succeeds in establishing his quality-ofreasoning view as a viable competitor theory. 